\title{
Society Leadership and Diversity: Hail to the Women!
}

$\mathrm{A}^{\mathrm{n}}$ landmark event occurred in Chicago at Digestive Disease Week (DDW) in May 2017. For the first time in history, all four gastroenterology and hepatology societies in the United States have women presidents: the American Association for the Study of Liver Diseases (AASLD), the American College of Gastroenterology (ACG), the American Gastroenterological Association (AGA), and the American Society for Gastrointestinal Endoscopy (ASGE). This occurrence was not the result of careful coordination, but a timing coincidence and a significant signal that the GI societies recognize the importance of diversity and inclusion for all our members.

Women comprise $43 \%$ of internal medicine residents, but represent only $16.4 \%$ of the 14,107 actively practicing gastroenterologists in the United States. ${ }^{(1)}$ The number of women entering gastroenterology fellowships is growing, and with that we hope to see more women in society leadership positions. Equality and diversity do matter. Our societies recognize the value of gender diversity within our organizations. Below, the opportunities available to women in gastroenterology to develop leadership skills are featured, in addition to the historic rise in the leadership of women in each society.

\section{The History of Women Presidents in GI Societies}

Founded in 1897, AGA is the oldest GI society, and it has had three women presidents: Dr. Sara Jordan (1942), Dr. Gail Hecht (2009), and now Dr.

Received July 20, 2017; accepted July 20, 2017.

Copyright (C) 2017 by the American Society for Gastrointestinal Endoscopy, American Gastroenterological Association, American College of Gastroenterology, and American Association for the Study of Liver Diseases

View this article online at wileyonlinelibrary.com. DOI 10.1002/hep.29392

Potential conflict of interest: Nothing to report.

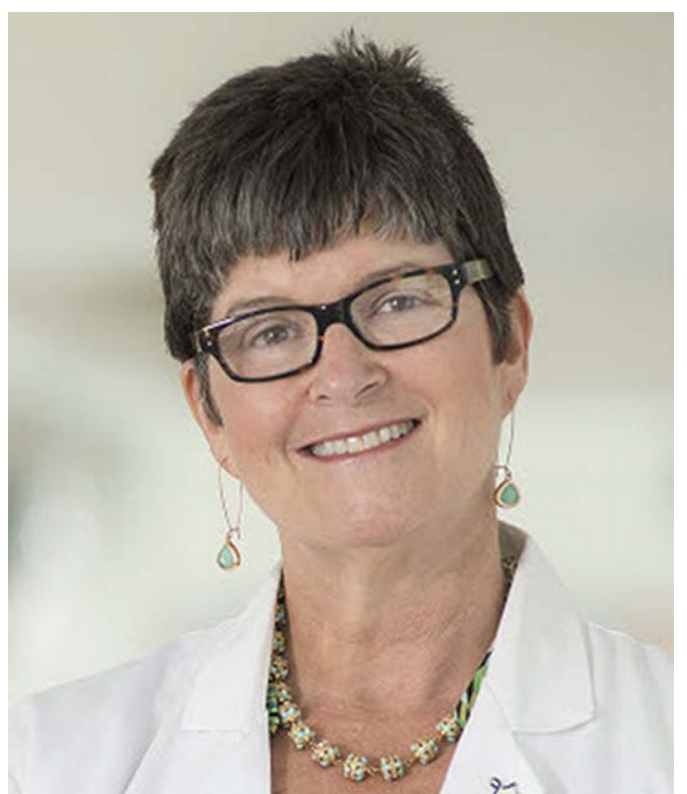

Carol A. Burke, M.D., FACG, FASGE, AGAF, FACP $A C G$ President

Sheila Crowe (2017). AGA was created to promote the common business interests of its members by promoting the image of the industry as a whole, to serve as a central, unified voice for the specialty of gastroenterology.

ACG was formed in 1932 by a group of private practice clinicians in the mid-Atlantic states to focus on meeting the educational and professional needs of clinical gastroenterologists. ACG has also had three women presidents: Dr. Christina M. Surawicz (1999), Dr. Amy E. Foxx-Orenstein (2008), and now Dr. Carol A. Burke (2017). Dr. Sunanda V. Kane will become president of the College in 2018.

In 1941, ASGE was founded to specialize in gastrointestinal endoscopy with a primary focus on training and education for endoscopic intervention, an area that, until recently, few women have specialized in. ASGE has had five women presidents: Dr. Marie Ortmayer (1955), Dr. Barbara Frank (1992), Dr. Grace 


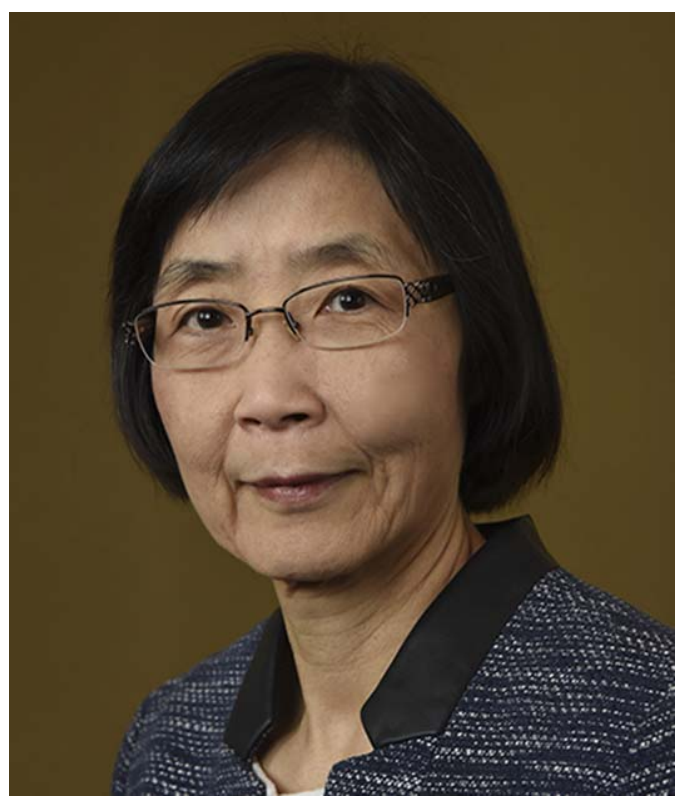

Anna Lok, M.D., D.Sc., FAASLD, AGAF AASLD President

Elta (2008), Dr. Colleen Schmitt (2015), and now Dr. Karen Woods (2017).

AASLD was created in 1950 and is comprised of scientists and health care professionals committed to preventing and curing liver disease. Hepatology has had many outstanding female role models, including the late Dame Sheila Sherlock-one of the founding parents of the specialty. AASLD has had four women presidents: Dr. Terry Wright (2005), Dr. Guadalupe Garcia-Tsao (2012), Dr. Gyongyi Szabo (2015), and now Dr. Anna Lok (2017).

\section{The Numbers Matter}

For many years, women have been important contributors to the GI societies and the profession, yet

TABLE 1. Percent (\%) of Members and Leaders in Each Society Who Are Women

\begin{tabular}{lcccc} 
& AASLD & ACG & AGA & ASGE \\
\hline Members (\%) & 33 & 21.5 & 24 & 16 \\
Trainee members (\%) & 44 & 33 & 34 & 27 \\
Fellows (\%) & 18 & 9.75 & 11 & 9 \\
Committee members (\%) & 40 & 26 & 35 & 28 \\
Committee chairs (\%) & 27 & 24 & 47 & 16 \\
Editors/Associate Editors of journals (\%) & 33 & 15.5 & 28 & 25 \\
Governing Board (\%) & 36 & $16^{*}$ & 23 & 32
\end{tabular}

*ACG Board of Trustees. they are still underrepresented in leadership positions. Recent data from the Association of American Medical Colleges (AAMC) identify that $38 \%$ of full-time, academic faculty are female, yet women account for only $21 \%$ of full professors and $15 \%$ of department chairs and deans. ${ }^{1}$ As the number of women in gastroenterology grows, there is an increasing need to address their needs as well as the needs of an increasingly diverse population of practicing gastroenterologists.

The GI societies recognize the importance of gender equality and are actively promoting involvement at multiple levels within the organizations. Current data in Table 1 list the percentage of women in each society and those who have reached leadership positions.

\section{Leadership Development Programs for Women in Gastroenterology}

The GI societies recognize the need to develop support programs for women in gastroenterology and have developed an impressive array of committees, special interest groups, and programs to support involvement and leadership development. It is hoped that these efforts will lead to increased involvement and recognition of the contributions of women in gastroenterology, which will enhance efforts to recruit and retain the growing cadre of women physicians in the field.

\section{COMMITTEES}

AASLD: Women's Task Force (will expand into a full committee in 2018)-Focused on creating networking and mentoring opportunities.

ACG: Women in GI Committee-Active in researching, highlighting, and mitigating gender disparities in our specialty and in medicine. This committee offers opportunities for female members to network, mentor, coach, and learn by sharing stories.

AGA: Women's Committee-Committed to fostering and promoting the involvement and advancement of women within the organization and the field, and addressing women's health issues.

ASGE: Member Engagement and Diversity committee-Focused on enhancing diversity by educating and training culturally competent gastroenterologists and providing leadership opportunities for all members. 


\section{PROGRAMS}

AASLD:

- Women's Network Luncheon at the annual meeting. Emphasis on ensuring gender balance and equal opportunities for men and women at all levels and in all committees within the society. For example, the Education Committee and Scientific Program Committees carefully review the proportion of women identified as potential speakers/moderators of each program, and the Nomination Committee ensures women are well represented in each committee.

ACG:

- Mentoring Program

- ACG Institute made a significant investment in cultivating the talents and skills of ACG members by sending them to national executive leadership training programs at some of the nation's most respected business schools. Of the 42 physicians who participated between 2009 and 2015, $26 \%$ were women.

- Women in GI Circle-online community (https://acg-women-in-gi.within3.com).

- Face-to-face offerings, such as the "Navigating, Networking and Negotiating Your First Job Workshop" and the "Career Opportunities for Women in GI Luncheon" at the ACG Annual Scientific Meeting.

\section{AGA:}

- AGA Women's Leadership Conference-provides leadership training, career guidance, and networking for early career and experienced women in the field.

- AGA Women's Talent Bank-serves as a resource for identifying qualified women members for leadership, recognition, and volunteer opportunities within AGA.

- Ergonomics Task Force-an outgrowth of the Women's Leadership Conference, the task force addresses work-related musculoskeletal injury and commonalities or differences based on gender. The long-term goal is to identify risks factors and develop metrics to minimize injury for both women and men.

- Annual Women in GI luncheon-held during DDW, the luncheon provides networking opportunities and showcases AGA's activities and commitment to women in the field.

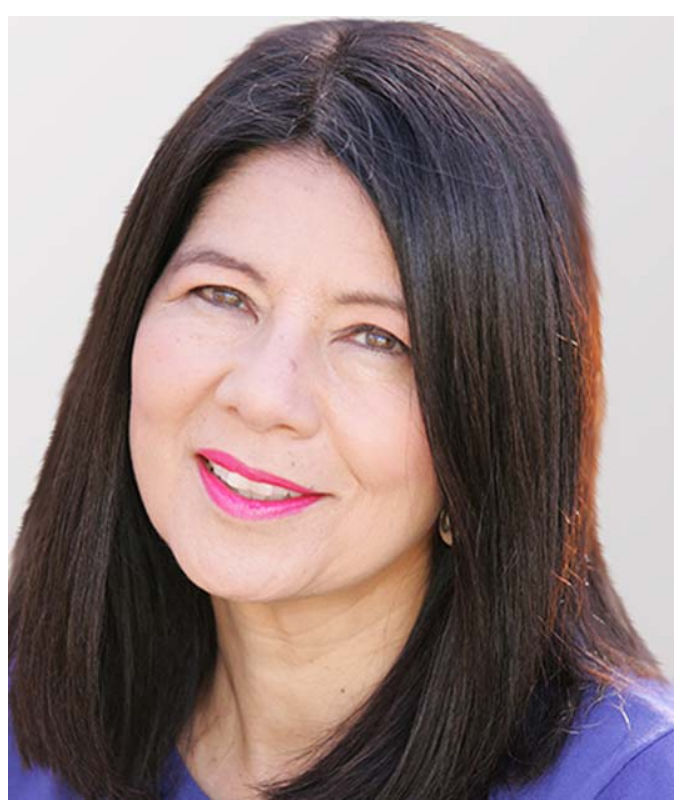

Sheila E. Crowe, M.D., FRCPC, FACP, FACG, AGAF $A G A$ President

ASGE:

- Mentorship Program-Pairs an experienced ASGE member with an up-and-coming GI professional

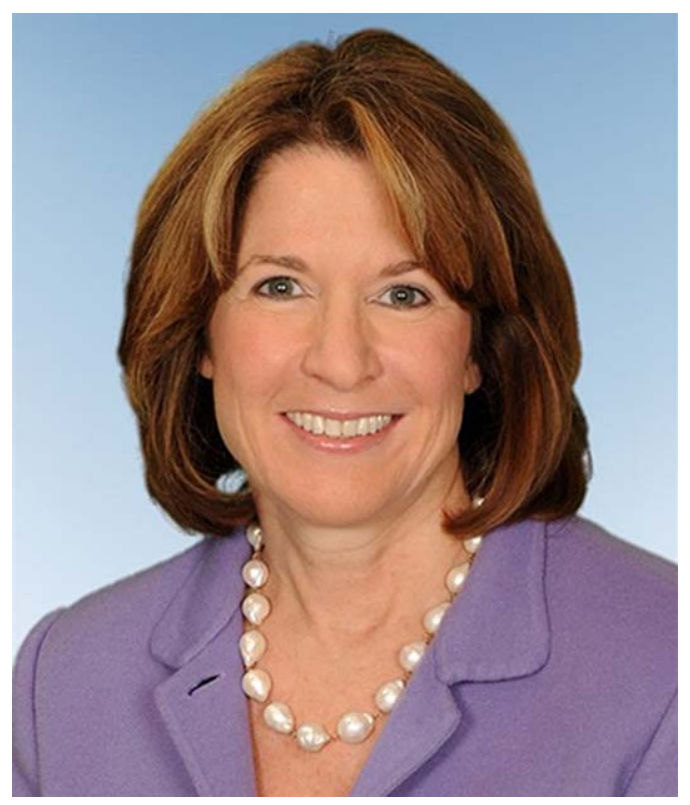

Karen L. Woods, M.D., FASGE ASGE President 
Women Presidents, from left: Drs. Karen Woods, Sheila Crowe, Carol Burke, and Anna Lok.

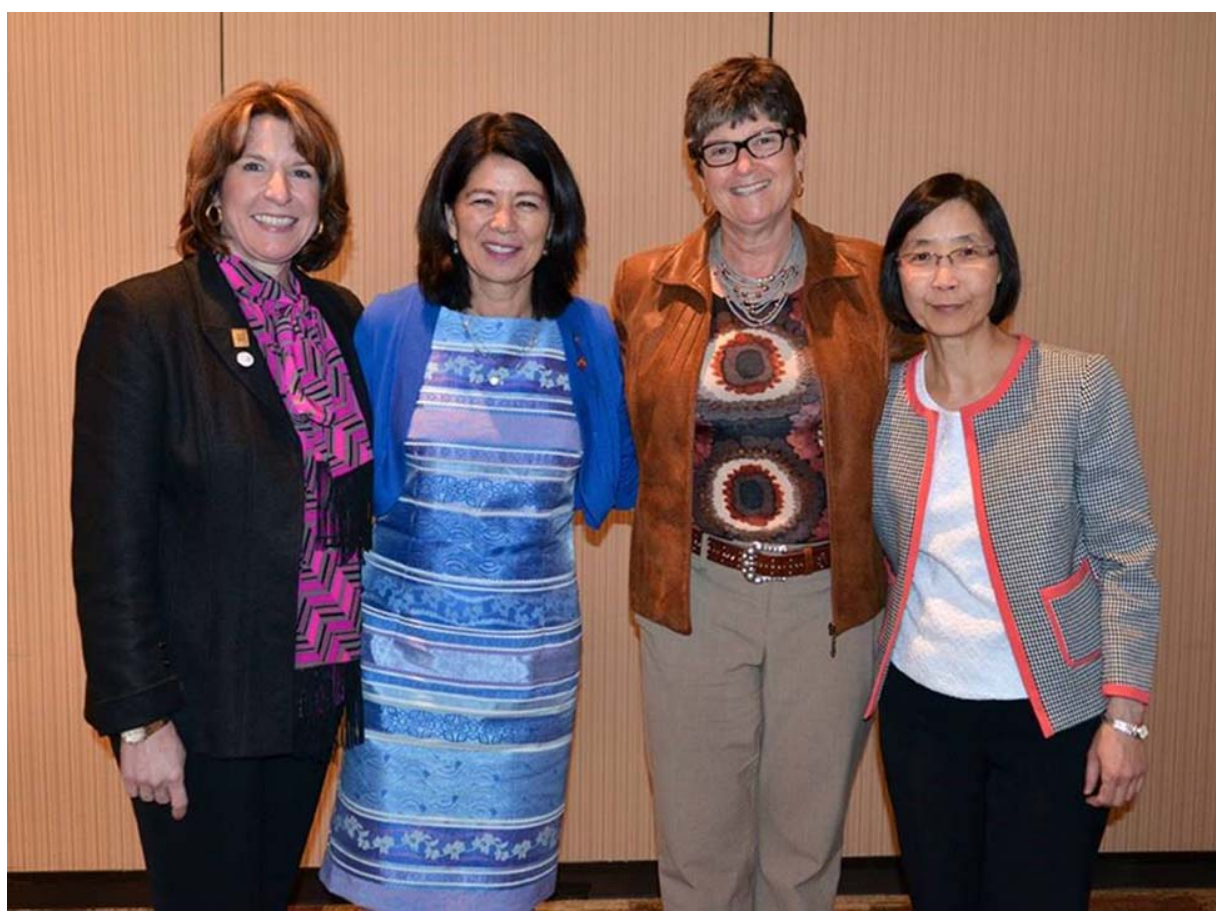

- Leadership Education and Development (LEAD) Program-LEAD is a 12 -month program offering young women gastroenterologists of all ethnic and cultural backgrounds an opportunity to enhance and energize their leadership and career development skills through education, coaching, and building professional networks. Participants must be nominated, and each year 20 young women are selected to participate.

\section{The Future}

The glass ceiling is not yet broken in our specialty. Ongoing initiatives are needed to require gender equality in all aspects of our profession. Medical societies and their leaderships must stand for equality, remove barriers, and continue to foster opportunities to build the cohort of emerging leaders in gastroenterology and hepatology. Our women's committees, mentoring and networking opportunities, and leadership skill acquisition programs are available and are having palpable impact on the success of women in our field.

As Presidents of the GI societies, our messages to women in gastroenterology and hepatology are based upon our own experiences: never underestimate your abilities, but always be honest in your self-assessment. Know your market value. Ask for and seek opportunities that interest you (even when others may have doubts). Serve others and your professional societies in whatever capacity you can.

We are proud to serve as the Presidents of the gastroenterology and hepatology societies representing all the women and men serving patients and working hard to ensure the future of this great profession. We thank you for this important opportunity.

\footnotetext{
Anna Lok, M.D., DS.c., FAASLD, AGAF (AASLD President), ${ }^{1}$

Carol A. Burke, M.D., FACG, FASGE, AGAF, FACP (ACG President), ${ }^{2}$

Sheila E. Crowe, M.D., FRCPC, FACP, FACG, AGAF (AGA President), ${ }^{3}$

Karen L. Woods, M.D., FASGE (ASGE President) ${ }^{4}$

${ }^{1}$ Division of Gastroenterology and Hepatology

University of Michigan

Ann Arbor, MI

${ }^{2}$ Department of Gastroenterology and Hepatology

Cleveland Clinic

Cleveland, $\mathrm{OH}$
} 
${ }^{3}$ Division of Gastroenterology

University of California

San Diego, CA

${ }^{4}$ Houston Methodist Gastroenterology Associates

Houston, TX

\section{REFERENCE}

1) Association of American Medical Colleges. Active physicians by sex and specialty, 2015. Available at: https://www.aamc.org/data/ workforce/reports/458712/1-3-chart.html. Accessed June 30, 2017. 